\title{
MENINGKATKAN EKSISTENSI PERKEMBANGAN PENDIDIKAN DAN DINAMIKA PERUBAHAN MASYARAKAT DI DESA SINGAMERTA KECAMATAN CURUG
}

\author{
Sri Ndaru Arthawati ${ }^{1}$ Sri Mukti Wirawati ${ }^{2}$ \\ ${ }^{1}$ Fakultas Ekonomi dan Bisnis, Universitas Sultan Ageng Tirtayasa, Jalan Raya Jakarta KM. 4, Panancangan, Banten \\ ${ }^{2}$ Teknik Industri, Universitas Banten Jaya, Jl Syech Nawawi Albantani Serang, Banten, Indonesia \\ Email: arthawatisri@gmail.com
}

\begin{abstract}
Education is a guideline in facing an era that is always developing with its progress. Concern for education is an important thing that must be considered and implemented based on the results of observations and data collection that have been carried out. Based on the results of observations and data collection, it was found that the Singamerta Village community lacked concern for the world of education. This can be seen from the large number of school children who do not continue their education to a higher level, and the lack of motivation of parents to send their children to school.
\end{abstract}

Keywords: Dynamics, Existence, Education, Change in Society

\begin{abstract}
ABSTRAK
Pendidikan merupakan pedoman dalam menghadapi zaman yang senantiasa berkembang dengan kemajuannya. Kepedulian terhadap pendidikan menjadi hal penting yang harus diperhatikan dan dilaksanakan berdasarkan hasil observasi dan pengumpulan data yang telah dilakukan. Berdasarkan hasil observasi dan pengumpulan data ditemukan kurangnya kepedulian masyarakat Desa Singamerta terhadap dunia pendidikan. Hal ini terlihat dari banyaknya usia anak sekolah yang tidak melanjutkan pendidikan ke tingkat yang lebih tinggi, dan kurangnya motivasi orang tua untuk menyekolahkan anak - anaknya.
\end{abstract}

Kata Kunci: Dinamika, Eksistensi, Pendidikan, Perubahan Masyarakat

\section{PENDAHULUAN}

Kelurahan Kamanisan Kecamatan Curug memiliki luas wilayah $531 \mathrm{Ha} / \mathrm{m}^{2}$, dengan batas wilayah sebelah utara Kelurahan Sukawana, sebelah selatan Kecamatan Baros, sebelah barat Kecamatan Pabuaran, dan sebelah timur Kelurahan Sukawana. Jumlah penduduk yaitu 7.570 jiwa diantaranya 3.941 jiwa laki laki dan 3629 jiwa perempuan, sedangkan jumlah kepala keluarga yaitu 1781 orang. Mayoritas masyarakat Kelurahan Kamanisan adalah masyarakat yang menganut agama islam yaitu sebesar 7561 jiwa. 


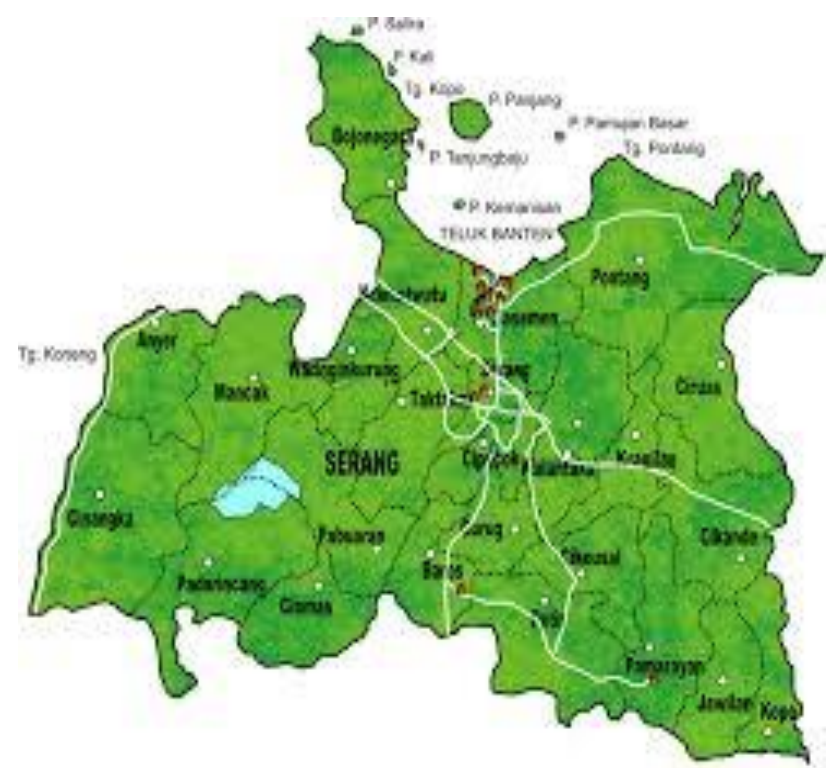

\section{Gambar 1. Peta Kelurahan Kamanisan Kecamatan Curug}

Menurut Undang Undang No 20 tahun 2003 Pasal 3 tentang Sistem Pendidikan Nasional, tujuan pendidikan nasional adalah untuk mengembangkan potensi peserta didik agar menjadi manusia yang beriman dan bertakwa kepada Tuhan Yang Maha Esa, berakhlak mulia, sehat, berilmu, cakap, kreatif, mandiri, dan menjadi warga negara yang demokratis serta bertanggung jawab. Menurut MPRS No 2 Tahun 1960, tujuan pendidikan adalah membentuk manusia yang berjiwa Pancasilais sejati berdasarkan ketentuan - ketentuan yang di kehendaki oleh pembukaan dan isi Undang Undang Dasar 1945. Kelurahan Kamanisan memiliki dua Sekolah Dasar Negeri salah satunya yaitu SDN Kubang. Berdasarkan observasi dan pengumpulan data, permasalahan pada bidang pendidikan yaitu masih rendahnya ilmu pengetahuan

Tabel 1. Tingkatan Pendidikan

\begin{tabular}{|c|l|c|}
\hline No & \multicolumn{1}{|c|}{ Tingkatan Pendidikan } & Jumlah (orang) \\
\hline 1 & Taman Kanak - Kanak & 85 \\
\hline 2 & SD/Sederajat & 474 \\
\hline 3 & SLTP/Sederajat & 3.041 \\
\hline 4 & SLTA/Sederajat & 2.932 \\
\hline 5 & Diploma & - \\
\hline 6 & Sarjana & 21 \\
\hline \multicolumn{2}{|c|}{ Jumlah Total (orang) } & $\mathbf{6 . 5 5 3 ~ o r a n g}$ \\
\hline
\end{tabular}


Tabel 2. Jumlah Lembaga Pendidikan

\begin{tabular}{|c|l|c|}
\hline No & \multicolumn{1}{|c|}{ Tingkatan Pendidikan } & Jumlah (sekolah) \\
\hline 1 & Taman Kanak - Kanak & 3 \\
\hline 2 & SD/Sederajat & 4 \\
\hline 3 & SLTP/Sederajat & 9 \\
\hline 4 & SLTA/Sederajat & 2 \\
\hline 5 & Universitas/Perguruan Tinggi & 2 \\
\hline 6 & Keagamaan & 6 \\
\hline \multicolumn{2}{|c|}{ Jumlah Total (sekolah) } & 26 sekolah \\
\hline
\end{tabular}

Pendidikan merupakan pedoman dalam menghadapi zaman yang senantiasa berkembang dengan kemajuannya. Kepedulian terhadap pendidikan menjadi hal penting yang harus diperhatikan dan dilaksanakan berdasarkan hasil observasi dan pengumpulan data yang telah dilakukan. Berdasarkan hasil observasi dan pengumpulan data ditemukan kurangnya kepedulian masyarakat Desa Singamerta terhadap dunia pendidikan. Hal ini terlihat dari banyaknya usia anak sekolah yang tidak melanjutkan pendidikan ke tingkat yang lebih tinggi, dan kurangnya motivasi orang tua untuk menyekolahkan anak - anaknya.

Di Kelurahan Kamanisan masih banyak dijumpai anak SLTP yang tidak dapat melanjutkan pendidikan ke tingkat SLTA karena faktor biaya, begitu juga sebaliknya dari tingkat SLTA tidak dapat melanjutkan pendidikan ke jenjang Perguruan Tinggi. Masih banyaknya usia anak sekolah yang tidak melanjutkan ke tingkat yang lebih tinggi, karena kurangnya kesadaran pada masyarakat akan pentingnya pendidikan. Sebagian warga memiki pemikiran bahwa untuk anak perempuan cukup untuk berumah tangga saja atau dengan kata lain menunggu untuk dilamar oleh lawan jenisnya sehingga tidak perlu melanjutkan pendidikan yang lebih tinggi, apalagi sampai ke jenjang Perguruan Tinggi. Cara berfikir seperti inilah yang harus di ubah karena pemikiran seperti itu sangat merugikan terutama bagi anak perempuan yang memiliki kemampuan dan keterampilan pengetahuan yang lebih baik. Selain itu, sarana prasarana yang belum memadai diantaranya kondisi ruang kelas yang harus diperbaiki dengan kondisi kaca jendela di beberapa kelas dalam keadaan pecah, kurangnya meja dan kursi di setiap ruang kelas, yang menyebabkan satu meja digunakan oleh banyak siswa, serta masih kurangnya tenaga pendidikan yang berdampak pada kurang efektifnya pembelajaran di sekolah. 


\section{METODE}

Dalam pelaksanaan kegiatan pengabdian masyarakat ini menggunakan beberapa metode antara lain: wawancara, catatan lapangan, dokumentasi, observasi, dan interview.

\section{HASIL DAN PEMBAHASAN}

Gambaran umum kelurahan Kamanisan kecamatan Curug adalah sebagai berikut

Lokasi pengabdian masyarakat di Kelurahan Kamanisan Kecamatan Curug. Batas - batas lokasi yaitu sebagai berikut:

1. Letak Geografis

a. Luas wilayah $: 531 \mathrm{Ha} / \mathrm{m}^{3}$

b. Batas wilayah

Sebelah utara : Kelurahan Sukawana

Sebelah selatan : Kecamatan Baros Kabupaten Serang

Sebelah barat : Kecamatan Pabuaran Kabupaten Serang

Sebelah timur : Kelurahan Sukawana

c. Ketinggian : $80 \mathrm{M} \mathrm{DPL}$

d. Orbitasi

Tabel 3. Orbitasi di Desa Singamerta

\begin{tabular}{|c|l|c|}
\hline No & \multicolumn{1}{|c|}{ Tujuan } & Jarak Tempuh \\
\hline 1. & Kantor Kecamatan & $3,5 \mathrm{Km}$ \\
\hline 2. & Kantor Perumnas & $13 \mathrm{Km}$ \\
\hline 3. & Kantor Pemprov & $5 \mathrm{Km}$ \\
\hline 4. & Ibukota Negara & 120 \\
\hline
\end{tabular}

e. Pengunaan Lahan

Permukiman : $59 \mathrm{Ha} / \mathrm{m}^{2}$

2. Keadaan Penduduk

Berdasarkan hasil observasi dan pengumpulan data yang diperoleh, mengenai keadaan penduduk di Kelurahan Kamanisan, Kecamatan Curug tercatat bahwa:

Jumlah penduduk 
a. Jumlah: 7.570 jiwa

Tabel 4. Jenis Kelamin Penduduk

\begin{tabular}{|c|l|c|}
\hline No. & \multicolumn{1}{|c|}{ Jenis Kelamin } & Jumlah \\
\hline 1. & Laki - laki & 3941 jiwa \\
\hline 2. & Perempuan & 3629 jiwa \\
\hline
\end{tabular}

b. Jumlah kepala keluarga: 1781 jiwa

c. Agama

Tabel 5. Agama yang Dianut oleh Penduduk

\begin{tabular}{|c|c|c|}
\hline No & Agama & Jumlah Orang \\
\hline 1. & Islam & 7561 \\
\hline 2. & Kristen & 9 \\
\hline 3. & Katolik & - \\
\hline 4. & Hindu & - \\
\hline 5. & Budha & - \\
\hline
\end{tabular}

Mayoritas masyarakat Kelurahan Kamanisan adalah masyarakat yang menganut agama islam sebanyak 7561 orang.

d. Lembaga kemasyarakatan

Tabel 6. Jenis Lembaga di Desa Singamerta

\begin{tabular}{|c|l|c|}
\hline No. & \multicolumn{1}{|c|}{ Jenis Lembaga } & Jumlah Pengurus \\
\hline 1. & PKK/ Organisasi Perempuan & 15 orang \\
\hline 2. & Organisasi Pemuda & 15 kelompok \\
\hline 3. & LPM/BKM & 9 orang \\
\hline 4. & Kelompok Gotong Royong & 17 kelompok \\
\hline 5. & Organisasi Profesi & - \\
\hline 6. & Organisasi Lainnya & - \\
\hline
\end{tabular}

3. Keadaan Pendidikan

Pendidikan merupakan pedoman dalam menghadapi perkembangan zaman yang senantiasa berkembang dengan kemajuannya. Kepedulian terhadap pendidikan menjadi hal penting yang harus diperhatikan dan dilaksanakan berdasarkan hasil observasi dan pengumpulan data yang telah dilakukan ditemukannya kurangnya kepedulian masyarakat Desa Singamerta terhadap dunia pendidikan. Hal ini terlihat dari banyaknya usia anak sekolah yang tidak melanjutkan ketingkat yang lebih tinggi, dan kurangnya motivasi orang tua untuk menyekolahkan anaknya. 
4. Keadaan Ekonomi

Data kependudukan Kelurahan Kamanisan kurang lebih 7.570 jiwa dengan jumlah penduduk laki - laki 3941 jiwa dan jumlah penduduk perempuan 3628 jiwa. Pada umumnya masyarakat Kelurahan Kamanisan bermata pencaharian sebagai petani, buruh tani, dan sebagian lagi berprofesi sebagai pegawai swasta, PNS, dan lain - lain.

Hal ini terlihat dari keadaan lahan pertanian yang sangat luas dan subur dan ini dapat dilihat berdasarkan jumlah mata pencaharian mereka sehari - hari yaitu:

Tabel 7. Jenis Mata Pencaharian di Desa Singamerta

\begin{tabular}{|c|l|c|}
\hline No. & \multicolumn{1}{|c|}{ Mata Pencaharian } & Jumlah (orang) \\
\hline 1. & Pegawai negeri & 18 \\
\hline 2. & TNI & 2 \\
\hline 3. & POLRI & 5 \\
\hline 4. & Tani & 215 \\
\hline 5. & Dagang & 40 \\
\hline 6. & Nelayan & 0 \\
\hline 7. & Pengrajin & 52 \\
\hline 8. & Peternak & 6 \\
\hline 9. & Montir & 68 \\
\hline 10. & Dokter & 0 \\
\hline 11. & Jasa lainnya & 99 \\
\hline Jumlah Total (orang) & 505 \\
\hline
\end{tabular}

Kepedulian terhadap pendidikan menjadi hal penting yang harus diperhatikan dan dilaksanakan berdasarkan hasil observasi dan pengumpulan data yang telah dilakukan. Berdasarkan hasil observasi dan pengumpulan data ditemukan kurangnya kepedulian masyarakat Desa Singamerta terhadap dunia pendidikan. Program dari kegiatan ini dapat menghasilkan antara lain:

1. Program Bimbel (Bimbingan Belajar).

Program bimbingan belajar merupakan bentuk kegiatan pendidikan yang dilakukan di Desa

Singamerta Kecamatan Curug. Program bimbingan belajar ini bertujuan untuk meningkatkan ilmu pengetahuan masyarakat agar memiliki kompetensi yang berguna untuk masa depan. 


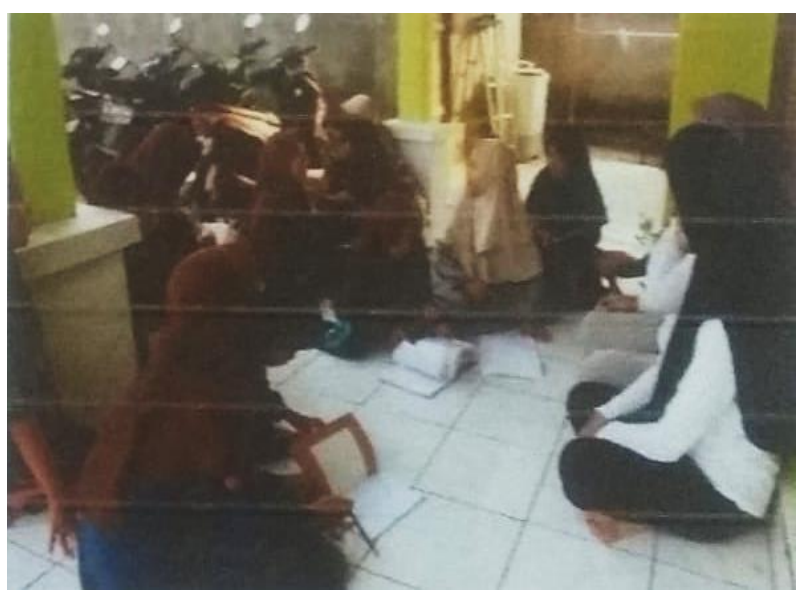

\section{Gambar 2. Program Bimbel}

2. Perpustakaan keliling.

Kegiatan perpustakaan keliling dilakukan secara berkala di Desa Singamerta Kecamatan Curug. Tujuan dari adanya perpustakaan keliling ini adalah untuk meningkatkan minat baca dan ketertarikan masyarakat terhadap ilmu pengetahuan.

3. Peta identifikasi masalah.

Peta identifikasi masalah merupakan metode identifikasi masalah pendidikan yang terjadi di Desa Singamerta Kecamatan Curug untuk memetakan masalah pendidikan sehingga dapat menganalisis masalah dan memberikan solusi terbaik untuk memecahkan masalah masalah pendidikan di Desa Singamerta Kecamatan Curug.

4. Perubahan mindset orang tua terhadap anaknya dalam bidang pendidikan melalui penyuluhan dalam majelis - majelis taklim/pengajian.

Keluarga merupakan tempat utama pendidikan pada anak. Oleh karena itu, perubahan mindset orang tua terhadap anaknya untuk meningkatkan pendidikan anak sangat diperlukan untuk mendorong keberhasilan anak. Kegiatan penyuluhan dalam majelis majelis taklim/ pengajian merupakan salah satu cara untuk merubah paradigma orangtua tentang pendidikan sehingga dapat menciptakan pola piker baru yang lebih maju untuk mendukung pendidikan di Desa Singamerta Kecamatan Curug.

5. Mengadakan permainan yang edukatif, bernyanyi, mengaji, pemberian kesan pesan, dan pemberian bingkisan kepada siswa sebagai bentuk apresiasi atas partisipasinya dikegiatan bimbingan belajar ini. 


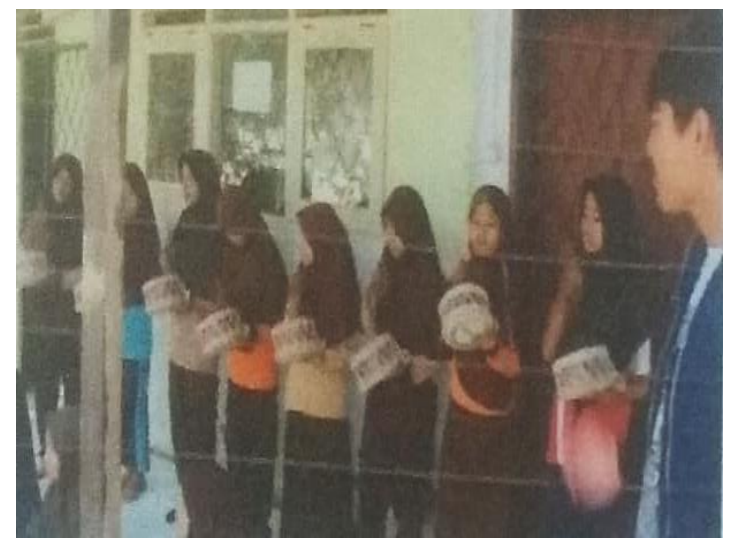

Gambar 3. Program Bimbel

6. Meningkatkan kualitas pendidikan siswa dalam bidang ilmu pengetahuan.

Kualitas pendidikan merupakan suatu hal yang penting untuk menyongsong masa depan generasi muda. Oleh karena itu, kualitas pendidikan perlu ditingkatkan dalam berbagai aspek dan ilmu pengetahuan agar dapat menciptakan generasi yang unggul, maju dan memiliki kompetensi.

Pendidikan adalah hal yang sangat dianggap penting di dunia. Dunia butuh orang-orang yang berpendidikan agar dapat membangun negara yang maju. Dalam hal inilah maka pendidikan diharapkan mengubah dunia menjadi lebih baik dan beradab. Maka dari itu pendidikan sangat penting kita dapatkan, karena jika kita tidak mempunyai ilmu dan pengetahuan kita akan mudah dipermainkan dan ditipu oleh orang lain. Dan pendidikan juga suatu proses kehidupan yang berguna untuk mengembangkan diri untuk dapat melangsungkan kehidupannya. sehingga menjadi orang terdidik sangatlah penting. Tetapi pada saat sekarang ini banyaknya generasi yang belum paham mengenai pendidikan yang benar dan juga tidak paham bahwa pendidikan itu sangat bermanfaat. Generasi sekarang banyak yang malas-malasan untuk sekolah dan menuntut ilmu. Hal ini terjadi karena generasi kini tidak paham seberapa pentingnya pendidikan.

Perpustakaan keliling adalah bagian perpustakaan yang diwujudkan dalam bentuk motor literasi sehingga dapat digunakan ke tempat - tempat tertentu, terutama tempat yang sulit dijangkau. Kegiatan perpustakaan keliling dilaksanakan pada jam istirahat sekolah di SDN Kubang, diawali dengan menyambut kedatangan para siswa/I setelah itu mengatur barisan agar tertib dalam mengisi data absen, peminjaman buku bacaan, dan membagikan buku bacaan yang ingin dipinjam oleh siswa. Sedangkan, untuk penyuluhan pendidikan dilaksanakan pada majelis - majelis taklim / pengajian yang rutin dilakukan selama sebulan dua kali. Sasaran dalam kegiatan 
ini adalah masyarakat Kelurahan Kamanisan khususnya masyarakat Kampung Kumbang Kecamatan Curug.

Pendidikan adalah salah satu hal yang penting kita perhatikan, pentingnnya pendidikan sangat terlihat jelas. Melamar pekerjaan yang layak tentu membutuhkan ijazah sesuai dengan jabatan yang akan kita lamar. Jabatan yang tinggi tentunya membutuhkan orang yang memiliki tingkat pendidikan yang tinggi juga yang dibuktikan dengan ijazah. Tapi apakah ijazah yang notabene merupakan simbol tingkat pendidikan sesorang berbanding lurus dengan pengetahuan yang dimiliki. Hal ini patut kita perhatikan dan amati bersama, apalagi di era globalisasi yang penuh persaingan dan tidak sedikit orang yang menghalalkan segala cara untuk memenangkan kompetisi tersebut.

Pendidikan pada dasarnya memberikan kita pengetahuan bagaimana bersikap, bertutur kata dan mempelajari perkembangan sains yang pada akhirnya bisa dimanfaatkan untuk khalayak banyak. Tapi apa yang terjadi sekarang pendidikan menjadi ajang untuk mencari nafkah uang, uang dan uang. Berbagai cara orang lakukan untuk mendapatkan label Sarjana agar dapat diterima pada sebuah instansi. Dan tidak sedikit yang menempuh jalur yang tidak benar yang biasa kita kenal dengan sogok menyogok dan Nepotisme.

Pentingnya pendidikan pun hilang ditelan ganasnya kebuasaan manusia yang hanya merasa hidup ketika berduit. Padahal pendidikan tidak mengajarkan seperti itu, pendidikan itu penting tapi sangat jarang orang mengetahui secara spesifik pentingnya pendidikan. Pendidikan dianggap penting karena dapat menjadi bekal untuk memperoleh pekerjaan yang layak. Padahal tujuan pendidikan tidak seperti itu, pendidikan penting karena ingin memanusiakan manusia sesuai dengan teori pendidikan. Pendidikan merupakan hal yang terpenting dalam kehidupan kita,ini berarti bahwa setiap manusia berhak mendapat dan berharap untuk selalu berkembang dalam pendidikan. Pendidikan secara umum mempunyai arti suatu proses kehidupan dalam mengembangkan diri tiap individu untuk dapat hidup dan melangsungkan kehidupan. Sehingga menjadi seorang yang terdidik itu sangat penting. Pendidikan pertama kali yang kita dapatkan di lingkungan keluarga, lingkungan sekolah dan lingkungan masyarakat. Seorang anak yang disayangi akan menyayangi keluarganya, sehingga anak akan merasakan bahwa anak dibutuhkan dalam keluarga. Sebab merasa keluarga sebagai sumber kekuatan yang membangunya. Dengan demikian akan timbul suatu situasi yang saling membantu,saling menghargai, yang sangat mendukung perkembangan anak. Di dalam keluarga yang memberi kesempatan maksimum pertumbuhan,dan perkembangan adalah orang tua. Dalam lingkungan keluarga harga diri berkembang karena dihargai,diterima,dicintai,dan dihormati sebagai manusia. Itulah pentingnya mengapa kita menjadi orang yang terdidik di lingkungan keluarga. Orang tua mengajarkan kepada kita mulai sejak kecil untuk menghargai orang lain. 
Sedangkan di lingkungan sekolah yang menjadi pendidikan yang kedua dan apabila orang tua mempunyai cukup uang maka dapat melanjutkannya ke jenjang yang lebih tinggi dan akan melanjutkan ke Perguruan Tinggi kemudian menjadi seorang yang terdidik. Alangkah pentingnya pendidikan itu. Guru sebagai media pendidik memberikan ilmunya sesuai dengan kemampuan yang dimiliki. Peranan guru sebagai pendidik merupakan peran memberi bantuan dan dorongan, serta tugas-tugas yang berkaitan dengan mendisiplinkan anak agar anak dapat mempunyai rasa tanggung jawab dengan apa yang dia lakukan. Guru juga harus berupaya agar pelajaran yang diberikan selalu cukup untuk menarik minat anak. Selain itu peranan lingkungan masyarakat juga penting bagi anak didik. Hal ini berarti memberikan gambaran tentang bagaimana kita hidup bermasyarakat. Dengan demikian bila kita berinteraksi dengan masyarakat maka mereka akan menilai kita,bahwa tahu mana orang yang terdidik,dan tidak terdidik. Di zaman Era Globalisasi diharapkan generasi muda bisa mengembangkan ilmu yang didapat sehingga tidak ketinggalan dalam perkembangan zaman. Itulah pentingnya menjadi seorang yang terdidik baik di lingkungan keluarga, sekolah, dan masyarakat.

\section{KESIMPULAN}

Kegiatan pengabdian masyarakat ini dilaksanakan di Desa Singamerta Kelurahan Kamanisan Kecamatan Curug. Berdasarkan kondisi lapangan yang diperoleh antara lain:

1. Aspek sarana dan prasarana penunjang pendidikan yang minim.

2. Aspek pendidikan karena kurangnya kesadaran masyarakat akan pentingnya pendidikan.

3. Dukungan masyarakat dan pemuda setempat sangat diharapkan lebih baik agar masyarakat memberikan motivasi betapa pentingnya pendidikan.

\section{DAFTAR ISI}

Undang Undang No 20 Tahun 2003 Pasal 3 tentang Sistem Pendidikan Nasional

Tap MPRS No 2 Tahun 1960 tentang Tujuan Pendidikan

Data Kependudukan Kelurahan Kamanisan Tahun 2018 